\title{
LA CÁRCEL COMO UTOPÍA DEL PROGRESO EXPERIENCIA VISUAL DEL PRESIDIO DE OLMOS
}

\author{
PRISON AS A UTOPIA OF PROGRESS \\ VISUAL EXPERIENCE OF OLMOS PENITENTIARY
}

Yasmin Angelozzi | yasangelozzi@gmail.com

Rocío Recatume | munirareca@gmail.com

Miranda Sánchez | agustina.bellasartes@gmail.com

Facultad de Bellas Artes. Universidad Nacional de La Plata. Argentina

Recibido: 6/4/2018 | Aceptado: 18/7/2018

\section{RESUMEN}

En el presente trabajo de investigación, realizado en el marco de la cátedra de Teoría de la Historia, nos proponemos, por un lado, indagar el modo de reconfiguración del espacio penitenciario en el siglo XX a partir del álbum de fotografías de la Unidad N. ${ }^{\circ} 1$ de Olmos, y, por otro, generar un análisis visual crítico de las imágenes que contiene en relación con el cambio de paradigma penitenciario.

\section{PALABRAS CLAVE}

Álbum; cárcel de Olmos; representación; obras públicas; sistema penitenciario

\section{ABSTRACT}

In the present research work, within the framework of the subject Teoría de la Historia, we will address the reconfiguration of the penitentiary space from the photographic album of Olmos penitentiary, as well as generate a critical visual analysis of the images that it contains in relationship with the change of the penitentiary paradigm of the $20^{\text {th }}$ century and its way of reconfiguring the space.

\section{KEYWORDS}

Album; Olmos penitentiary; representation; public works; penitentiary system 
Esta investigación comienza en el Archivo Histórico y Museo del Servicio Penitenciario Bonaerense creado en 1994 con la misión de recolectar, conservar y difundir el patrimonio documental de las unidades penitenciarias desde su origen, en 1887. Además, conserva, estudia, difunde y exhibe el patrimonio cultural e histórico institucional. Los documentos y los objetos que forman parte de su acervo expresan los conceptos penalistas y criminológicos establecidos desde los inicios del sistema penitenciario provincial hasta nuestros días, como así también preserva colecciones artísticas realizadas por los internos. La dependencia está conformada por una biblioteca y por el archivo, que almacenan documentos sobre las distintas unidades de la provincia, legajos y libros de entrada de internos hombres y mujeres. Cuenta, además, con salas de exposición que conforman el museo, destinadas a la colección permanente de los objetos históricos y a muestras temporales. A través de un proceso de búsqueda y de reinterpretación del material documental seleccionado, las fotografías de la Unidad N. ${ }^{\circ} 1$ de olmos contenidas en el álbum Banco Crédito Provincial serán pensadas en su contexto, para aproximarnos a la propuesta visual de la época.

Luego de obtener la autorización de ingreso al archivo y con el material disponible a consultar, nos encontramos con falta de documentación y de registro acerca del origen del álbum, de su ingreso al archivo y de sus condiciones de producción. Algunos de estos datos fueron aportados por los trabajadores del museo, quienes nos informaron que el libro fue encargado por la empresa constructora del presidio como regalo al Banco Crédito Provincial por financiar la obra, con la intención de registrar el proyecto finalizado que les fue encargado y llega al archivo, casualmente, como donación.

Entonces, con esta información asumimos un doble desafío. Por un lado, tratar de esclarecer los interrogantes que nos interpelan al contacto con el álbum: ¿quién tomó las fotografías?, ¿con qué función?, ¿han circulado estas imágenes por fuera de este objeto? Por otro lado, intentaremos aproximarnos a un análisis visual crítico de las fotografías, en relación con el edificio que registran: ¿đe qué manera las imágenes se vinculan con el cambio de paradigma penitenciario propio del siglo XX?

Con las preguntas en mente nos enfrentamos, en primera instancia, a nuestro objeto de estudio: un antiguo bibliorato de finales de los treinta, de tamaño considerable, cuyos márgenes y lomo se encontraban, a simple vista, deteriorados por el paso del tiempo. Se veía primoroso y, a la vez, apaleado. Para su manipulación se recomendó el uso de guantes a modo de conservación preventiva.

A primera vista, nos trasladó de inmediato a un espacio de amplitud, líneas rectas y asepsia, inverosímil para la idea de prisión que subyace en nuestro imaginario. La idea de cárcel modelo resuena una y otra vez en todo el recorrido de aquel álbum que cristaliza un modelo destinado al fracaso. Podríamos retomar, entonces, la idea
1 El cambio de paradigma penitenciario se relaciona con el pasaje de una sociedad colonial a la toma de conciencia de las ideas de la modernidad. Este proceso de cambio se ve directamente relacionado con la adopción de las ideas de modernidad, manifestadas en la construcción de nuevas cárceles a fines del siglo XIX y principios del siglo $X X$. Los edificios adoptan el sistema radial panóptico y una visión higienista privilegia la iluminación y la ventilación de algunos espacios. 
de archivo de Arlette Farge (1991): «El archivo es una desgarradura en el tejido de los días, el bosquejo realizado de un acontecimiento inesperado. Todo él (el archivo) está enfocado sobre algunos instantes de la vida de personajes ordinarios, pocas veces visitados por la historia» (p. 11).

Para darle sustento a nuestro estudio, consultamos material del acervo de la biblioteca del Archivo. Finalmente, luego de una exhaustiva búsqueda, logramos dar con publicaciones de finales de la década los treinta, como la revista Penal y Penitenciario (1939) y la publicación Obro Pública (1940), donde figuran las obras realizadas en los municipios de la provincia de Buenos Aires, en el periodo que va de 1936 a 1940. Allí rastreamos una posible circulación oficial de las fotografías del álbum, cuestión que retomaremos más adelante. No contábamos con material institucional que pudiera brindarnos información sobre las imágenes más que lo escrito dentro del álbum en sí mismo, que revisamos detalladamente, y la bibliografía trabajada en el marco de la asignatura, que se adecuó a la temática de nuestro trabajo de investigación y nos brindó las herramientas conceptuales.

\section{VALOR DOCUMENTAL VERSUS VALOR ESTÉTICO}

El álbum de la cárcel de Olmos [Figura 1] contiene una serie de fotografías del año 1939 realizadas por un fotógrafo/a desconocido/a [Figura 2]. Se encuentran encuadernadas en un álbum de gran formato y de cuero teñido, cuya portada contiene una placa de chapa labrada que, a modo de umbral, conecta el exterior con su interior. Los detalles de la arquitectura, así como las despensas y todos los servicios de los que el edificio disponía fueron cristalizados, minuciosamente, en cada fotografía.

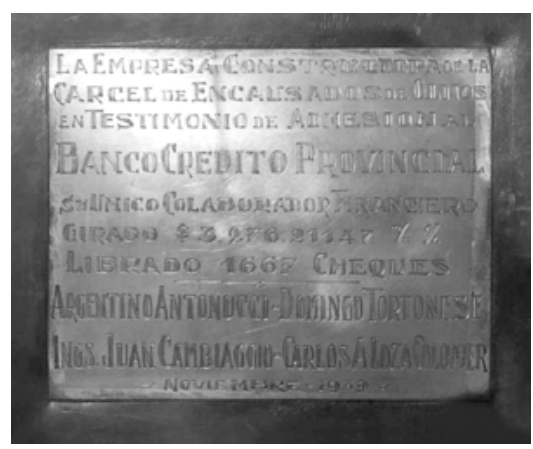

Figura 1. Detalle de la portada del álbum (1939). Archivo Penitenciario de la provincia de Buenos Aires 


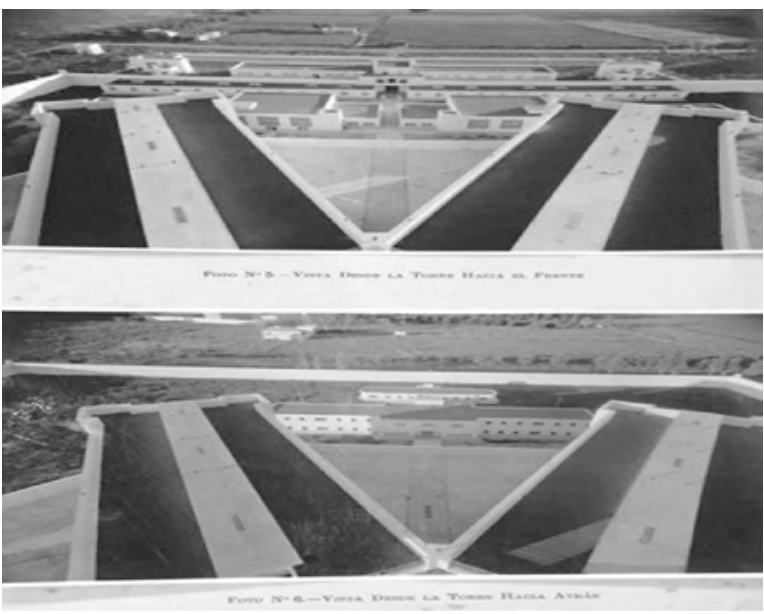

Figura 2. Fotografías de la Unidad N. ${ }^{1} 1$ de Olmos (1939). Interior del Álbum Bonco Crédito Provincial. Archivo Penitenciario de la provincia de Buenos Aires

La concepción de este álbum como documento es devorada por la calidad estética de las fotografías que dificultan la posibilidad de pensarlas como un mero registro. Encontramos en ellas cierta intencionalidad en el modo de representar estos espacios, un programa visual predeterminado que construye de una cárcel una utopía.

Sin embargo, si tomamos en cuenta el dispositivo utilizado, podríamos considerar las imágenes que pertenecen al álbum como documentos que sirven para reconstruir los contenidos de la mentalidad de la época. Siempre y cuando podamos discernir de una noción positivista, que entiende al documento como algo objetivo. El documento no es una mercancía estancada del pasado, sino un producto de la sociedad que lo ha fabricado. De acuerdo a jacques Le Goff (1991), todo documento es consciente o inconscientemente un montaje de la historia, de la época y de la sociedad que lo ha construido y, también, de las épocas ulteriores en las que ha continuado viviendo. A partir de esto tomaremos al documento como monumento.

\section{ITINERARIO DE LAS IMÁGENES}

En el transcurso de nuestra investigación, hemos develado que las imágenes que componen el álbum circularon en distintas revistas de carácter oficial, lo que nos lleva a interrogarnos sobre sus condiciones de reproducción, ¿cómo llegaron a difundirse por estos ámbitos? 


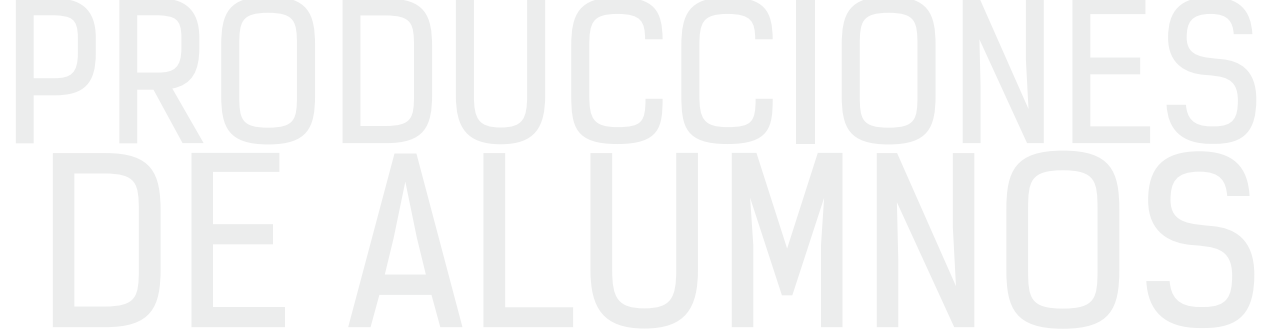

Para reflexionar sobre este punto, comenzamos a indagar en la fotografía de la arquitectura de Estado. En este recorrido, notamos que el Ministerio de Obras Públicas (MOSP), actual Ministerio de Infraestructura de la provincia de Buenos Aires, desde el año 1906, aproximadamente, incorpora la fotografía como método de registro y, de esta manera, da cuenta del proceso y del resultado de las obras emprendidas por la gobernación, como testimonio documental.

\footnotetext{
En la provincia de Buenos Aires, el gobierno de Fresco² animó e impulsó las nuevas funciones del Estado interventor y regulador, a partir de formas novedosas de concebir la política, el Estado y las relaciones sociales resultantes de ese vínculo, nociones propias del «clima de época». En ese marco, durante los años treinta las obras públicas adquirieron nuevos significados: por su alta visibilidad en el espacio público operaban como representación de la acción estatal y como mecanismo o dispositivo de legitimación política de gobiernos cuya vía de acceso al poder, como el de Fresco, había sido allanada por la apelación a prácticas fraudulentas (Fernández, 2015, p. 18).
}

Sabemos, gracias a las fuentes, que estos registros se volcaron y se organizaron en grandes biblioratos, en los que se explicitan los datos edilicios de la obra, de la locación, de los autores, etcétera. En el periodo temporal que va desde los comienzos de la utilización de la técnica fotográfica en el MOSP hasta finales de 1939 no se registran nombres de autores. Si nos detenemos en este punto, podemos trazar un paralelismo con el álbum de la cárcel de Olmos, donde no encontramos la autoría de quien disparó esas tomas. "Estas fotografías no eran fotografías firmadas por el fotógrafo a cargo, sino que era el organismo el que figuraba como responsable de testimoniar y controlar aquellas obras» (Harasic \& Troisi, 2014, p. 5).

No fue hasta la década del cuarenta que las imágenes comenzaron a firmarse en los reversos, pero por cuestiones de conservación, que limitaron su manipulación, no pudimos determinar si este es el caso. De este modo, estas fotografías funcionan como registro material de la obra realizada, resguardadas como documentos en estos álbumes de gran tamaño, pero también eran estas mismas fotos las que circulaban en el boletín oficial. «Estos fotógrafos trabajaban para el Ministerio, y el objetivo encomendado era dejar asentada la presencia del Estado en el seguimiento de las etapas constructivas, en donde la fotografía era el registro del cumplimiento y del avance de las obras» (Harasic \& Troisi, 2014, p. 5).

Volviendo al álbum de la cárcel de Olmos, queremos remarcar que las fotografías que contiene han sido documentos esenciales dentro del programa de política publicitaria del gobierno de turno. Esto queda certificado a través de las revistas y las publicaciones antes mencionadas [Figura 3], que se hicieron a cargo de la
2 Manuel Antonio Fresco fue gobernador de la provincia de Buenos Aires entre 1936 y 1940 por el partido conservador Demócrata Nacional. 


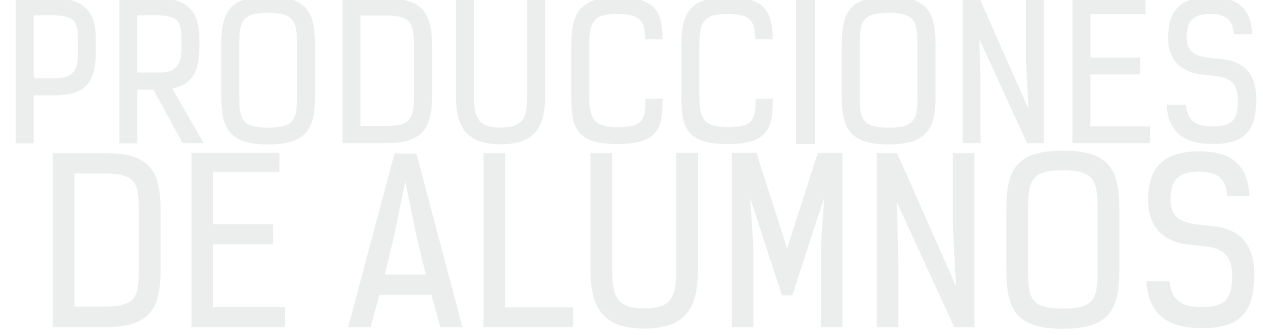

provincia en los años de la inauguración de la cárcel. A pesar de que desde el archivo se apela al álbum como un obsequio de la constructora al Banco Crédito Provincial, la circulación de estas imágenes por ámbitos oficiales y de propaganda política, como también los puntos de contacto que vislumbramos entre la fotografía de registro estatal realizada por los talleres del MOSP, nos suscita más interrogantes que certezas: ¿cómo explicamos su circulación en estas publicaciones?

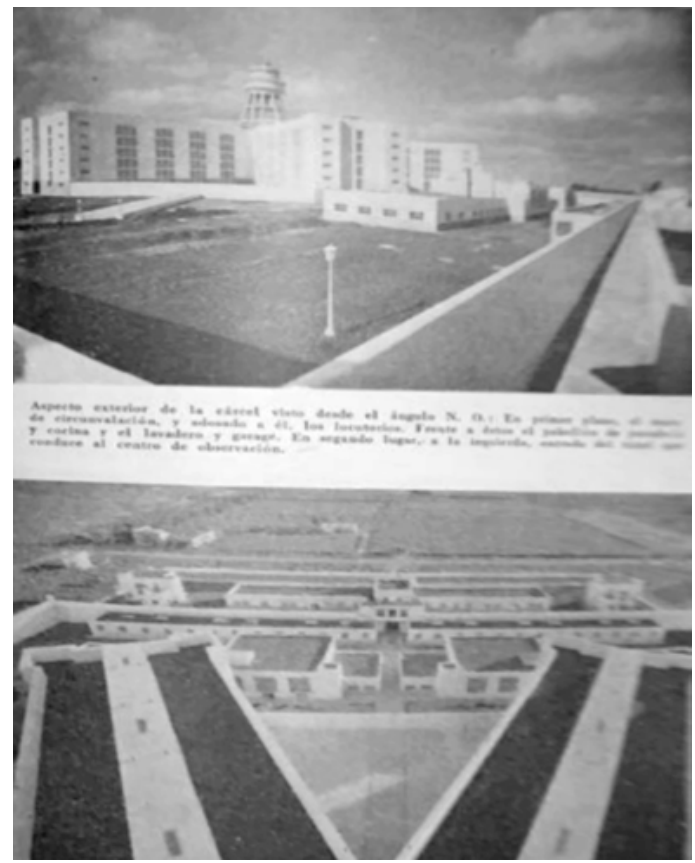

Figura 3. Fotografías de la Unidad 1 de Olmos pertenecientes al Álbum Bonco Crédito Provincial, publicadas en la Revista Penal y Penitenciaria (1939). Archivo Penitenciario de la provincia de Buenos Aires

\section{GRAN ILUSIÓN: EL RELATO FOTOGRÁFICO DEL PRESIDIO}

La Unidad N. ${ }^{\circ} 1$ [Figura 4], ubicada en la localidad de Lisandro Olmos, partido de La Plata, comenzó su construcción en 1935 y se inauguró el 18 de noviembre de 1939. Esta emblemática unidad fue puesta en funcionamiento bajo la gestión provincial del Dr. Manuel Fresco. La capacidad inicial de la obra fue planeada para albergar a 1300 internos, construida para dar respuesta a las necesidades del Departamento Judicial de la Capital, y como reemplazo de la vetusta cárcel platense de 1 y 59 y de la existente en la Jefatura de Policía. Su estructura 
arquitectónica es radial, consta de pabellones distribuidos en seis plantas y en cada una de ellas se ubican doce pabellones colectivos que convergen a un núcleo central en forma hexagonal, en el cual se ubica un gran patio para iluminación y aireación de diferentes dependencias.

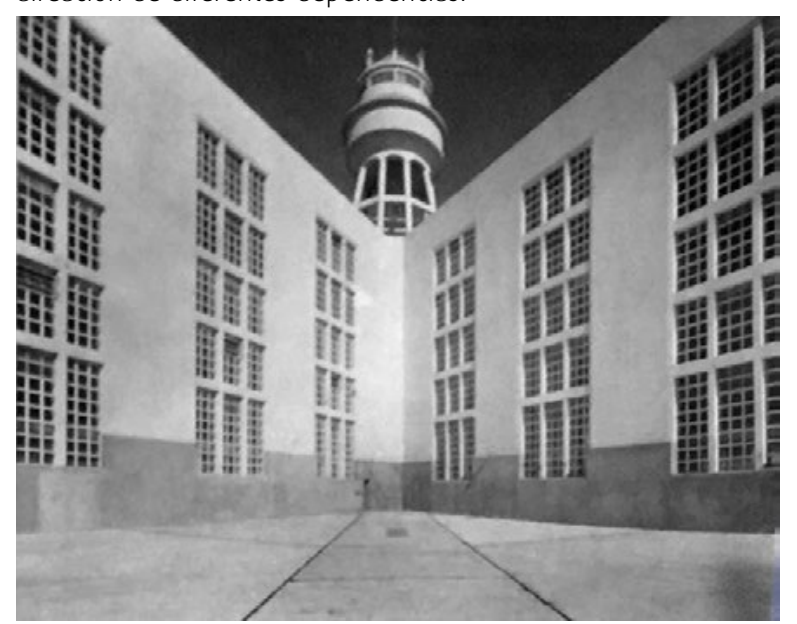

Figura 4. Patio de la cárcel de Olmos (1939). Álbum Banco Crédito Provincial. Archivo Penitenciario de la provincia de Buenos Aires

En el proyecto del edificio se advierte la toma de decisiones por parte de los ingenieros civiles Juan Cambiaggio y Carlos Loza Colomera (a cargo de la monumental construcción). La estructura adaptada en este establecimiento es una combinación del sistema radial de Ghent de 1773 (Francia), primer establecimiento carcelario orientado bajo una base científica de reclusión, y el de sing sing de 1825 (Estados Unidos), en cuanto a la disposición de celdas. Por lo tanto, no se ha seguido la idea generatriz del panóptico, como es normal en la mayoría de los establecimientos ingleses o alemanes.

Concebimos la fotografía del patio del presidio de Olmos no como una presencia directa del mundo visible, sino "como una estructura de elementos visuales» (Aumont, 1992, p. 158). La composición visual de la imagen está distribuida en dos mitades iguales que se organizan a partir de un eje central, que a la vez funciona como punto de fuga. Por encima del edificio, y para rematar la composición simétrica, se eleva una torre de vigilancia. Las paredes que allí vemos están compartimentadas por ventanas que, a modo de módulos, se repiten rítmicamente. En esta composición se pueden observar dos de los doce pabellones colectivos que conforman la unidad. Se hace notable, y a la vez eficiente, el uso del punto de fuga para dar cuenta de aquel innovador sistema hexagonal que caracteriza la 


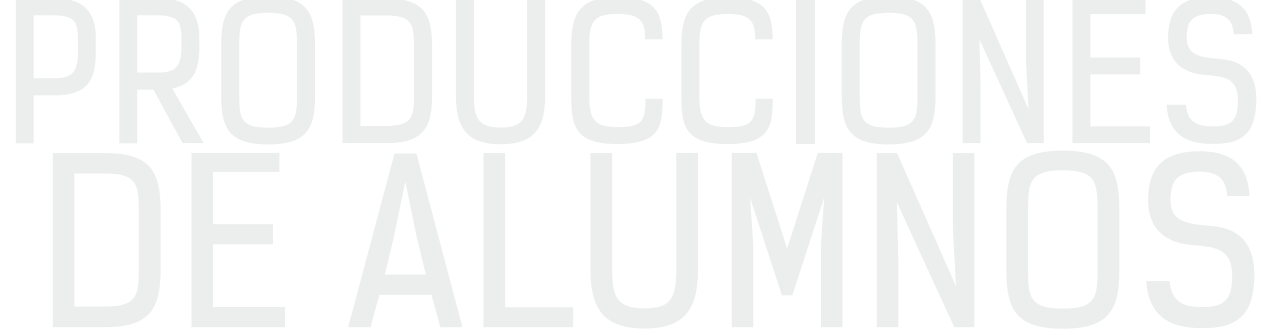

construcción. Los tipos de encuadre elegidos por el fotógrafo, así como también la decisión de que no haya presencia humana, acentúan la monumentalidad y el carácter ascético del edificio representado.

La idea de un diseño que contemple la conformación de un patio de recreo refuerza el relato de estar frente a un cambio de paradigma moderno, en el cual el recluso tiene acceso a un momento de ocio y relajación. Como sugiere en el álbum el ingeniero civil de la construcción Carlos Loza Colomer respecto al aspecto funcional carcelario, "este aspecto (funcional carcelario), ha sido meticulosamente estudiado en cada caso, con respecto a la vida diaria del encausado, la que ha sido reglamentada en horas de labor, de recreo y de descanso» (Unidad N. ${ }^{\circ} 1$ de Olmos, 1939, p. 18).

Si analizamos comparativamente las fotografías del penal de olmos con las de otros edificios de obras públicas contemporáneas que forman parte del mismo programa político, como el caso del pabellón de tuberculosos ubicado en el Hospital San Juan de Dios [Figura 5] o la vista del patio interior de la Casa Cuna, podemos evidenciar ciertas diferencias. Tanto en las decisiones compositivas como en el modo de representar la arquitectura pública, esto podría dar cuenta de la falta de un programa de representación pautado. Esto también demuestra que muchas de estas elecciones varían de acuerdo al equipo fotográfico.

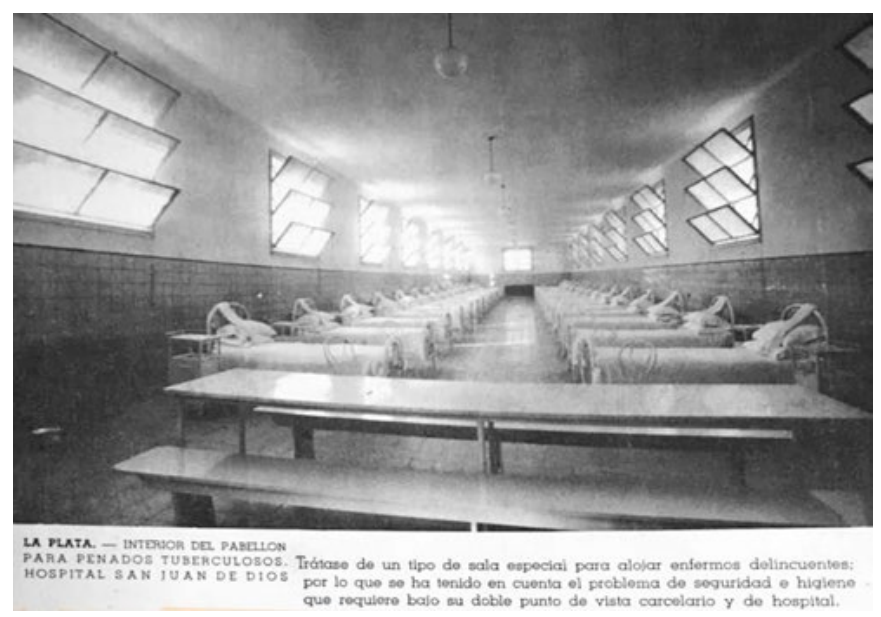

Figura 5. Interior del pabellón para penados tuberculosos ubicado en el hospital San Juan de Dios (1940) Fuente: Obras Públicas, vol. 1. Biblioteca del Archivo Penitenciario de la provincia de Buenos Aires 
Si esbozamos las similitudes, también vemos en estas láminas el uso de la perspectiva a un punto de fuga para generar una idea de mayor espacialidad. El recurso de la repetición generada por las ventanas, así como en el caso del Hospital, dada por las camas para enfermos, nos hace pensar en la capacidad con la que fue diseñada la construcción. Para nada se trata aquí de edificios pequeños, sino, más bien, todo lo contrario; se ven proyectados (incluso también en las fotografías) el sentimiento de orgullo generado por las construcciones nacionales. Espacios aireados y bien iluminados vistos en dichas fotografías, son comparables con las que obtuvimos de la Unidad N. ${ }^{0} 1$ de Olmos.

Consideramos apropiado mencionar como una característica afín entre los edificios representados el hecho de que se los retrata de un modo en que contrastan, ampliamente, con su funcionalidad y, de esta manera, tensionan la imagen.

Ahora bien, reflexionemos sobre las fotografías de la cárcel. En primer lugar, si pensamos en cualquier cárcel o presidio, difícilmente se nos venga a la mente una imagen pulcra, de líneas limpias y sin personas. Estas fotografías difieren con la realidad, no tanto por la distancia temporal que las separa del momento en el que fueron tomadas, sino en que no coinciden con el sentido de uso de la institución [Figura 6]. Un espacio para ser ocupado no concuerda con la imagen pulcra y vacía en la que consisten estas fotografías. El corte temporal que supuso el cierre del obturador dejó atrapado, junto con las partículas de luz, un desierto tan alejado de la realidad como problemático.

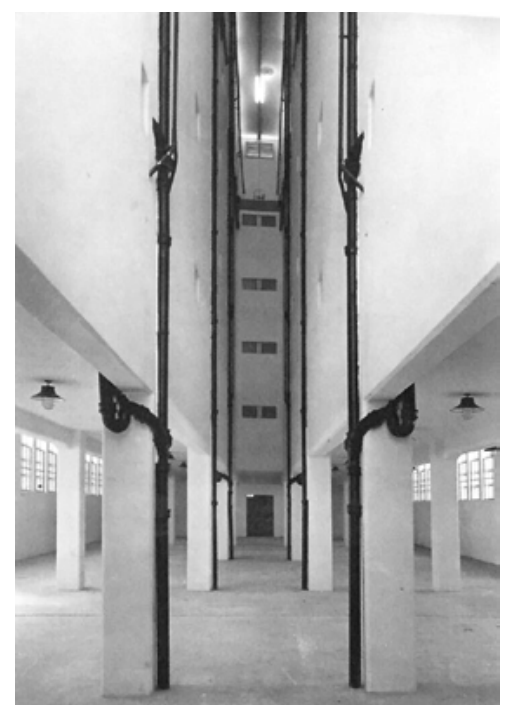

Figura 6. Vista de talleres y pozo central de ventilación de la cárcel de olmos (1939). Álbum Banco Crédito Provincial. Archivo Penitenciario de la provincia de Buenos Aires 


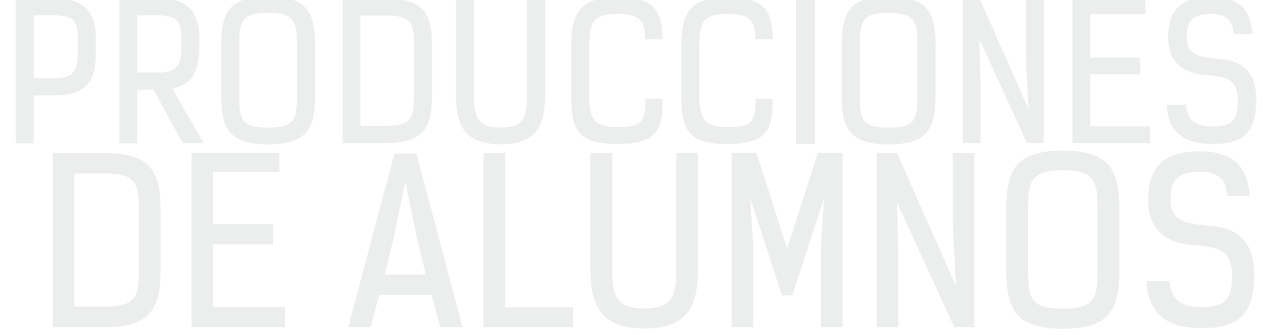

Aquí la fotografía se ve cada vez más sutil y moderna. Resulta, entonces, interesante la transfiguración lograda por los/as fotógrafos/as que alcanzaron con ellas correr del foco de atención a quienes iban a convivir dentro de esas estructuras fotografiadas, para decirnos que lo que se encuentra ahí no es otra cosa que algo bello, pulcro y reluciente.

Esta nueva forma de representación en las fotografías se corresponde con la crítica que le hace Walter Benjamin [1934] (2009) a la representación estética del horror, promulgada por la fotografía de la Nueva Objetividad en Alemania. «Han conseguido convertir incluso la miseria en directo objeto de disfrute» (p. 305). El valor instrumental del edificio queda anulado y pasa a ser de carácter puramente estético. Es decir, se pierde la noción formo-contenido para pasar a cobrar una mayor importancia la forma en la presentación de esas fotografías que transforman la realidad de la función de una cárcel para solo mostrarnos ilustraciones agradables a la vista. De esta manera, la desgracia se convierte en objeto estético y, como sabemos, la cárcel es un sitio de castigo y la forma de representación propuesta de este espacio no hace más que negar su funcionalidad.

Como hemos esbozado hasta aquí, consideramos que el modo en que los espacios son fotografiados se corresponde con la aparición de las nuevas prácticas institucionales implementadas por el sistema penitenciario sobre técnicas novedosas de vigilancia, archivo, disciplina, formación y reforma.

Comienza una revolución en cuanto a los métodos penitenciarios, en el que se replantea qué hacer con el detenido. Esta fase es conocida como correccionalista moralizadora, ${ }^{3}$ donde el castigo físico y la retribución con trabajo dejan de contemplarse como los únicos medios. Es por eso que vemos en la imagen una intención de reconfigurar el espacio. Estas fotografías estetizan este modo de segregación social y niegan lo que allí, a pesar del cambio paradigmático, sigue ocurriendo:

\footnotetext{
[... esas maneras eran incomparables con las hipótesis que se venían sosteniendo sobre la naturaleza de la modernización de la prisión. Unas tras otras las estadísticas hablaban de la superpoblación de las cárceles vetustas, las disfunciones en la articulación del sistema judicial que saturaba sus instalaciones [...] Había otra historia, la de la abrumadora mayoría de las instituciones carcelarias, que se emparentaban mucho más con las tradiciones punitivistas coloniales (Caimari 2017, p. 43).
}

Con esto decimos que, a pesar del intento de modernización del sistema carcelario a partir de los modos de vigilancia que ocurrían en Europa y en Norteamérica, en este caso evidenciado al ver la arquitectura de la cárcel modelo de Olmos, en la realidad de los prisioneros nada cambiaba.
3 La fase correccionalista nace a finales del siglo XVIII extendiéndose hacia los finales del siglo XIX, cuando se concibe la pena de prisión y con ella la sanción penal del recluso en establecimientos que comienzan a crearse y que resultaron la base del actual régimen penitenciario. El modelo tenía por fin erradicar las sanciones corporales comenzando una nueva forma de administrar castigos. Dicho modelo se basaba en la aplicación de cuatro reglas o normas: aislamiento absoluto, prohibición de trabajo, silencio absoluto y educación religiosa. 


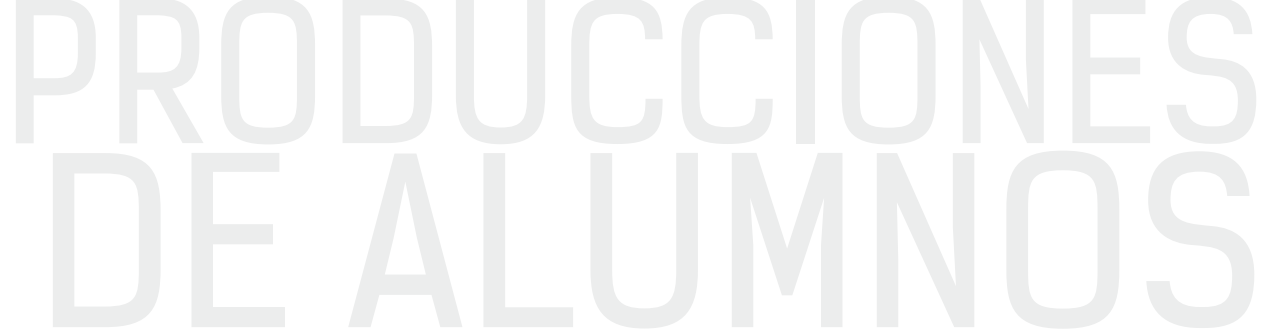

\section{CONSIDERACIONES FINALES}

El recorrido de esta investigación concluye en que no hay mirada inocente. La forma en que un espectador ve una imagen se basa en comparaciones con nuestro conocimiento previo del mundo (Aumont, 1992). Asimismo, se intentó desentramar el relato propuesto por las fotografías que componen el álbum del presidio de Olmos a partir de un análisis crítico de su modo de representación, que resulta tensionado al visualizar un espacio de castigo completamente estetizado, donde se vislumbra un intento de cárcel modelo y esconde las viejas prácticas más brutales bajo el umbral de lo que no se ve.

Es por ello que vemos en la obra de Benjamin (2009) un disparador esencial para repensar las intenciones de las fotografías que componen este álbum. Actualmente, el fracaso de la cárcel modelo, que fue diseñada minuciosamente, se ve materializado en la superpoblación, el hacinamiento y las malas condiciones que sufren los internos. Finalmente, gracias al trabajo de archivo pudimos vislumbrar la doble función del objeto de estudio analizado. Por un lado, su función documental, a través de los mecanismos de distribución y difusión de las imágenes, y, por otro lado, se destaca su función como monumento, en el que se considera al álbum como un entramado de relaciones (que se dieron entre el fotógrafo/a, el arquitecto de dicha construcción y el Banco Crédito Provincial) donde se crea un escenario a través de las tomas para construir esa idea moderna, perpetuar el recuerdo y ser atesorado en un futuro próximo. Monumento como un legado a la memoria colectiva.

La experiencia del trabajo en archivo, en la cual por momentos el pánico de la desinformación se volvía abrumador, nos sirvió para encontrar otros puntos de enfoque que permitirían arribar a las conclusiones antes mencionadas. Y, en última instancia, para preguntarnos si quizás la parte más fascinante de nuestro trabajo como futuras historiadoras del arte consiste en el esfuerzo continuo de hacer hablar a las cosas mudas, de hacerles decir lo que solas no dicen sobre los hombres, sobre las sociedades que las han producido, y de constituir, finalmente, esta vasta red de solidaridad y de ayuda recíproca que suple la falta del documento escrito.

\section{REFERENCIAS}

Aumont, J. (1992). En Lo imagen. Buenos Aires, Argentina: Paidós.

Benjamin, W. [1934] (2009). El autor como productor. En Obras. Libro II / vol. 2 (pp. 297-315). Madrid, España: Abada. 
Caimari, L. (2017). Lo vido en el archivo. Goces, tedios y desvíos en el oficio de la historia. Buenos Aires, Argentina: Siglo XXI.

Farge, A. (1991). Lo atraccción del archivo. Valencia, España: Edicions Alfons El Magnánim, Institución Valenciana de Estudios e Investigación.

Fernández, N. (2015). Políticas estatales y obras públicas en la provincia de Buenos Aires, 1917-1943. Ponencia dictada durante las V Jornadas de Becarios y Tesistas. Universidad Nacional de Quilmes, Buenos Aires, Argentina.

Harasic, C.; Troisi, R. (2014). Lo Fotografía de Arquitectura en el Estado. Ponencia dictada durante el $11^{\circ}$ Congreso de Historia de la Fotografía en la Argentina. Centro de Documentación e Investigación de la Arquitectura Pública (CeDIAP). Ministerio de Economía y Finanzas Públicas, Buenos Aires, Argentina.

Le Goff, J. (1991). La crítica de los documentos: hacia los documentos/ monumentos. En El orden de la memoria (pp. 234-239). Buenos Aires, Argentina: Paidós.

Ministerio de Justicia e Instrucción Pública de la Nación (1939). Revisto penal y penitenciario (H260). Biblioteca del Archivo Penitenciario de la provincia de Buenos Aires.

Ministerio de Obras Públicas de la provincia de Buenos Aires (1940). Obras Públicas, Vol. 1. (H321). Biblioteca del Archivo Penitenciario de la provincia de Buenos Aires.

Unidad N. 1 de Olmos (1939). Álbum Banco Crédito Provincial. Buenos Aires, Argentina: Archivo Penitenciario de la provincia de Buenos Aires. 